\title{
Linear frequency tuning in an LC-resonant system using a C-V response controllable MEMS varactor
}

\author{
Chang-Hoon Han ${ }^{1,2}$, Yong-Hoon Yoon', Seung-Deok Ko ${ }^{1}$, Min-Ho Seo ${ }^{1}$ and Jun-Bo Yoon ${ }^{*}$ (e)
}

\begin{abstract}
This paper proposes a device level solution to achieve linear frequency tuning with respect to a tuning voltage $\left(V_{\text {tune }}\right)$ sweep in an inductor $(L)$-capacitor $(C)$ resonant system. Since the linearity of the resonant frequency vs. tuning voltage $(f-V$ relationship in an $L C$-resonant system is closely related to the $C-V$ response characteristic of the varactor, we propose a $C-V$ response tunable varactor to realize the linear frequency tuning. The proposed varactor was fabricated using microelectromechanical system (MEMS) surface micromachining. The fabricated MEMS varactor has the ability to dynamically change the $C-V$ response characteristic according to a curve control voltage $\left(V_{\text {curve-control }}\right)$. When $V_{\text {curve- }}$ control was increased from zero to $9 \mathrm{~V}$, the $C-V$ response curve was changed from a linear to a concave form (i.e., the capacitance decreased quickly in the low tuning voltage region and slowly in the high tuning voltage region). This change in the $C-V$ response characteristic resulted in a change in the $f-V$ relationship, and we successfully demonstrated almost perfectly linear frequency tuning in the $L C$-resonant system, with a linearity factor of $99.95 \%$.
\end{abstract}

Keywords: C-V response, Linearity, LC-resonant system, Microelectromechanical systems (MEMS) varactor, Resonant frequency, Voltage-controlled oscillator (VCO)

\section{Introduction}

Today's multi-band wireless communication devices and systems use various frequencies, and therefore require frequency tunable modules, which have been the subject of continuous study. Among them, the voltage-controlled oscillator (VCO) is one of the key components for changing the output frequency in wireless communication systems. Among its various characteristics, the linearity of the VCO's output frequency tuning is a critical figure-of-merit in most applications. For example, the linearity of the output frequency sweep is directly connected to the range accuracy of the frequency modulation continuous wave (FMCW) radar system [1]. In phase-locked loop circuits, it is known that the nonlinear frequency tuning characteristic in a VCO is one of the main sources affecting phase noise degradation [2].

\footnotetext{
*Correspondence: jbyoon@kaist.ac.kr

${ }^{1}$ School of Electrical Engineering, Korea Advanced Institute of Science and Technology (KAIST), 291 Daehak-ro, Yuseong-gu, Daejeon 34141, Republic of Korea

Full list of author information is available at the end of the article
}

In the common $\mathrm{VCO}$, which uses inductor $(L)$-capacitor $(C)$ resonant systems $(L C-V C O)$, a varactor is the main device for changing the output frequency [3]. Solid-state varactors based on semiconductors, however, produce a fixed $C-V$ response curve that is not suitable for a linear $f-V$ response, and it is not changeable once it is fabricated. As a result, it is difficult to linearize the output frequency response with conventional varactors. Accordingly, there have been notable efforts to linearize the $f-V$ response by employing specifically designed circuits [4-6]. However, these complicated circuits tend to increase the cost of the system design and consume more electrical power, which are undesirable features.

To address these problems, this study focused on the $C-$ $V$ response of the varactor itself, to achieve linear frequency tuning in the $L C$ resonant system without any circuit based support. First, we sought the kind of $C-V$ response characteristic necessary to achieve the linear frequency tuning. Then a MEMS varactor satisfying the required $C-V$ response characteristic was designed and fabricated using 
surface micromachining. At this step, the core concept for this kind of varactor was adopted from the previous paper [13]. However, since the capacitor needs to be connected with an inductor to demonstrate linear $f-V$ tuning in this paper, the design and fabrication process were fully modified to achieve the goal. The fabricated MEMS varactor was then integrated with a monolithically fabricated spiral inductor to verify its effect on frequency linearization.

\section{Proposed concept and design}

\section{Required C-V response}

Figure 1a represents the basic $L C-V C O$ circuit. Since the oscillation occurs at the resonant frequency of the connected inductance $(L)$ and the effective capacitance $\left(C_{e f f}\right)$ at the node of $x$ or $y$, the oscillation frequency is described as follows:

$$
f_{o}=\frac{1}{2 \pi \sqrt{L C_{\text {eff }}}}=\frac{1}{2 \pi \sqrt{L\left(C_{\text {tune }}+C_{p}\right)}}
$$

where, $C_{\text {tune }}$ is the capacitance of the varactor and $C_{p}$ is the parasitic capacitance, if any, at the node of $x$ or $y$.

The ideal linear output oscillation frequency response with respect to the tuning voltage $\left(V_{\text {tune }}\right)$ is hypothetically plotted in Fig. 1b. The straight line in Fig. 1b is expressed as follows:

$$
f_{\text {o_ideal }}=\alpha V_{\text {tune }}+\beta
$$

where, $\alpha$ is the gradient of $f_{\text {o_ideal }}$ vs. $V_{\text {tune }}$ graph, and $\beta$ is the intercept value of the vertical axis $\left(f_{\text {o_ideal }}\right.$ at $V_{\text {tune }}$ is zero). By plugging $f_{o}$ in (1) into $f_{o_{-} \text {ideal }}$ in (2), the following relationship is deduced:

$$
\mathrm{C}_{\text {tune }}=\frac{1}{4 \pi^{2}\left(\alpha \mathrm{V}_{\text {tune }}+\beta\right)^{2} \mathrm{~L}}-\mathrm{C}_{\mathrm{p}}
$$

Next, a reasonable boundary condition is set to determine $\alpha$ and $\beta$. The minimum and maximum tuning voltages $\left(V_{\text {tune }}\right)$ are set as 0 and $15 \mathrm{~V}$, respectively, and the capacitances for each voltage are set to be $900 \mathrm{fF}$ $(V=0 \mathrm{~V})$ and $400 \mathrm{fF}(V=15 \mathrm{~V})$, respectively, for operation at frequency ranges of several $\mathrm{GHz}$. According to (3), the $L$ value does not affect the $C-V$ response shape, and in this work it is set to $2 \mathrm{nH}$ to obtain several $\mathrm{GHz}$ output oscillation frequencies.

Figure 1c represents the required $C_{\text {tune }}-V_{\text {tune }}$ response in (3) in order to achieve the linear output frequency tuning characteristic shown in Fig. $1 \mathrm{~b}$ for several parasitic capacitances $\left(C_{p}\right)$. As can be seen in Fig. 1c, we need a concave shape in the $C-V$ response of the varactor, and more importantly, the $C-V$ response characteristic should be changeable (tunable), since the $C_{p}$ might be unknown or vary from system to system.
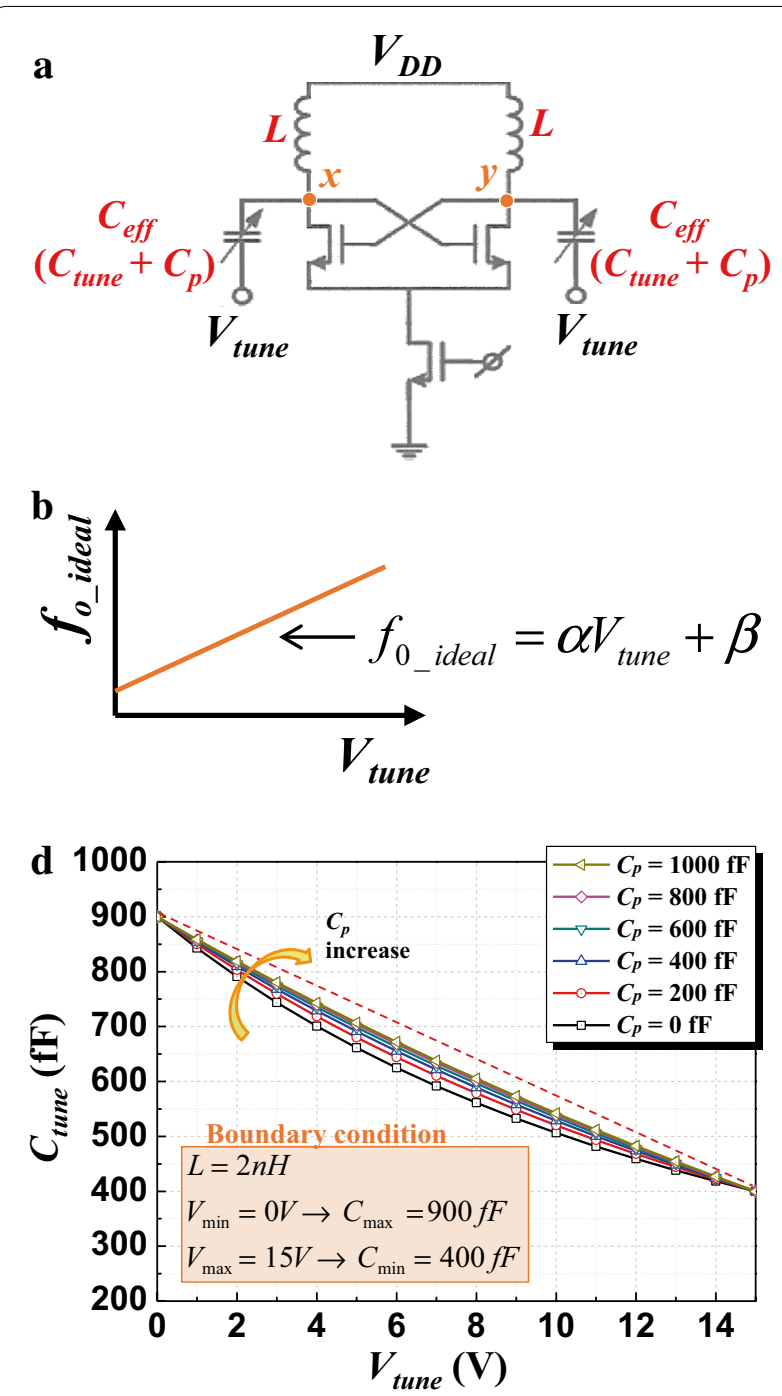

Fig. 1 Ideal linear frequency tuning in $L C-V C O$. a Basic components of the LC-VCO circuit, $\mathbf{b}$ ideal linear output frequency tuning characteristic, $\mathbf{c}$ required $C_{\text {tune- }} V_{\text {tune }}$ response to achieve linear frequency tuning, with various parasitic capacitances, $C_{p}$

\section{Proposed MEMS varactor}

There have been a lot of works on RF MEMS capacitors to acquire a unique property that is not easily achieved by the conventional semiconductor-based technology [7-11]. These works tell that the MEMS capacitors have much more flexibility in the design that determines the $C-V$ response. Therefore, we made use of the MEMS technology to satisfy the specific $C-V$ response. Although, it has integration issues, the MEMS variable capacitor provides two main benefits: a possibly high Q-factor from its high conductive metal signal path, and variable tuning characteristic even adaptive to unknown parasitic components. 
Figure 2a describes the proposed MEMS varactor, which can realize the required $C-V$ response discussed in the previous section. The capacitance is formed between the top and bottom plates in the capacitor section. When the tuning voltage ( $\left.V_{\text {tune }}\right)$ is applied to the $V_{\text {tune }}$ electrode, the tuning plate in the actuator section (electrically grounded) moves down due to the electrostatic force. Then, the top plate in the capacitor section is lifted up by the seesaw mechanism, making the capacitance smaller. This increasing-gap actuation can give us a linearly decreasing $C-V$ characteristic, shown as a dotted line in Fig. 2b [12].

The proposed MEMS varactor shown in Fig. 2a has an another electrode, which is a curve-control electrode, to control the $C-V$ response curve shape. The initial position of the top plate in the capacitor section is closer to the bottom plate as we apply $V_{\text {curve-control }}$. This results in an increase in the initial capacitance (at $V_{\text {tune }}=0 \mathrm{~V}$ ) in the $C_{\text {tune }}-V_{\text {tune }}$ curve, as shown in Fig. 2b (solid line), while the final capacitance (at the maximum tuning voltage) is preserved, since the $V_{\text {curve-control }}$ loses its attractive effect as the control plate moves up. Therefore, as

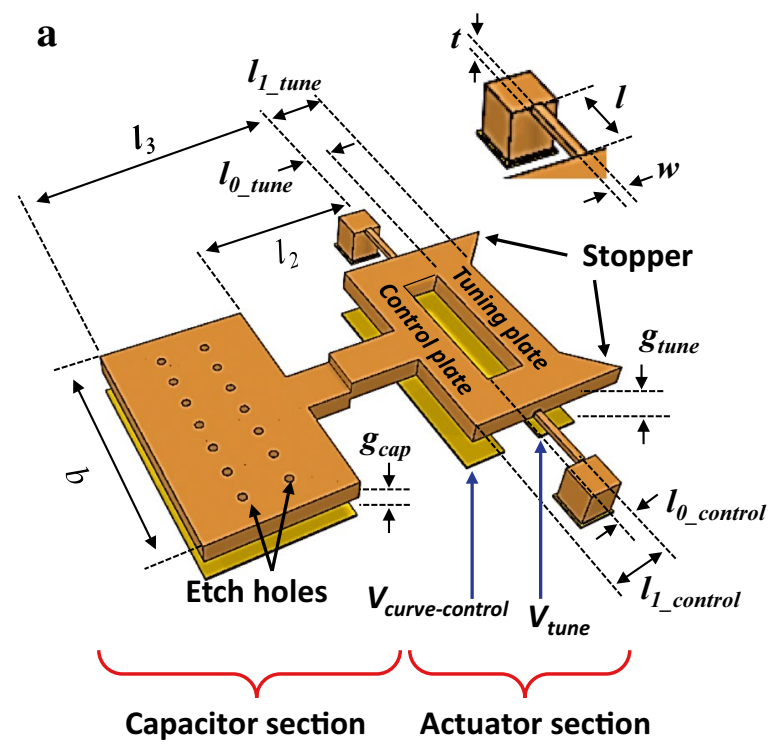

b

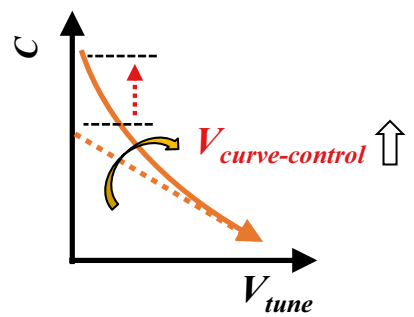

Fig. 2 Proposed MEMS varactor employing a levering actuator. a Perspective view, b tunable $C-V_{\text {tune }}$ characteristic with respect to $V_{\text {curve-control }}$ we increase $V_{\text {curve-control }}$, the shape of the $C-V_{\text {tune }}$ curve becomes a more concave form [13]. In this way, we can control the $C-V$ response characteristic of the varactor to accommodate the parasitic capacitance, to eventually achieve the linear output frequency tuning discussed in Fig. 1.

\section{Design of the structural parameters}

This section details the process of designing dimensional parameters. Therefore, the author suggests that readers who are not interested in the designing process skip this section.

To achieve the linear $f-V$ response, it is beneficial to set the initial $C-V$ response curve to be linear when the curve control voltage is zero $\left(V_{\text {curve-control }}=0 \mathrm{~V}\right)$. According to previous works, the linearity of the $C-V$ response is mainly determined by the ratio of $l_{2}$ and $l_{3}[12,13]$ shown in Fig. 2a. When $l_{3}$ increases leaving $l_{2}$ unchanged from the optimal length showing a linear $C-V$ response, the $C-V$ curve is changed to a concave form. On the other hand, as $l_{3}$ decreases without changing $l_{2}$, the $C-$ $V$ response is turned into a convex shape. In addition, another variable exists in this work: The ratio of the gap height between the capacitor section and the actuator section. In other words, the length of $l_{3}$ (which determines the total length of the varactor) can be shortened by reducing the gap in the capacitor section so that it is smaller than that of the actuator section. Taking these points into account, the capacitance in the capacitor section can be described as follows:

$$
\mathrm{C}_{\text {cap }}=\int_{\mathrm{l}_{2}}^{\mathrm{l}_{3}} \frac{\varepsilon \mathrm{b}}{\mathrm{l} \theta+\mathrm{g}_{\text {cap }}} \mathrm{dl} \cong \frac{\varepsilon\left(\mathrm{l}_{3}-\mathrm{l}_{2}\right) \mathrm{b}}{\frac{\left(\mathrm{l}_{3}+\mathrm{l}_{2}\right)}{2} \theta+\mathrm{g}_{\text {cap }}}
$$

where, $\varepsilon$ is permittivity and $\theta$ is a rotational angle that has positive value as the capacitor plate moves up. Since the rotational angle of the proposed device is small enough, the additionally increasing height in the capacitor section can be simply expressed as $l \times \theta$.

For simpler calculation, it can be assumed that the rotational movement of the capacitor section is a parallel plate actuation [13]. Therefore, the integral form can be re-written as the right hand side of (4). As a result, the expression for the capacitor section can be arranged by $\theta$, as follows;

$\theta=\left(\frac{\varepsilon \mathrm{b}\left(\mathrm{l}_{3}-\mathrm{l}_{2}\right)}{\mathrm{C}_{\text {cap }}}-\mathrm{g}_{\text {cap }}\right) \frac{2}{\left(\mathrm{l}_{3}+\mathrm{l}_{2}\right)}=\mathrm{f}_{\mathrm{I}}\left(\mathrm{C}_{\text {cap }}, \mathrm{g}_{\text {cap }}, \mathrm{l}_{2}, \mathrm{l}_{3}\right)$

Next, in the actuator section, the well-known equation that models the rotational movement with respect to the input voltage is adopted, as follows $[13,14]$ : 


$$
\begin{aligned}
\mathrm{T}_{\text {tune }}= & \frac{\varepsilon \mathrm{bV}_{\text {tune }}^{2}}{2 \theta_{\text {max }}^{2}}\left(\frac{1}{2}\left(1-\gamma^{2}\right)+\frac{2}{3} \frac{\left(1-\gamma^{3}\right) \theta}{\theta_{\max }}+\frac{3}{4} \frac{\left(1-\gamma^{4}\right) \theta^{2}}{\theta_{\max }^{2}}\right. \\
& \left.+\cdots+\left(\frac{\mathrm{n}+1}{\mathrm{n}+2}\right)\left(1-\gamma^{\mathrm{n}+2}\right)\left(\frac{\theta}{\theta_{\max }}\right)^{\mathrm{n}}\right)
\end{aligned}
$$

where, $T_{\text {tune }}$ is an electrostatic torque generated by the tuning voltage input, $\gamma$ is $l_{0_{-} \text {tune }} / l_{1_{-} \text {tune }}$, and $\theta_{\text {max }}$ is $g_{\text {tune }} / l_{l_{-} \text {tune }}$. Here, we separate the variable for the gap of the tuning electrode $\left(g_{\text {tune }}\right)$ from the one in the capacitor plate $\left(g_{\text {cap }}\right)$ to increase the freedom of design while the previous model used one fixed variable for those two values [13]. Therefore, as a result, we can reduce total length of the capacitor by controlling the rate of $g_{\text {tune }}$ and $g_{\text {cap }}$ with high $C-V$ response tunability.

By expanding (6) with $n=2$, the following equation is deduced:

$$
\begin{aligned}
& \mathrm{T}_{\text {tune }}=\frac{\varepsilon \mathrm{bV}_{\text {tune }}^{2} \mathrm{l}_{1 \_ \text {tune }}^{2}}{2 \mathrm{~g}_{\text {tune }}^{2}}\left(\frac{1}{2}-\frac{1}{2} \frac{\mathrm{l}_{0 \_ \text {tune }}^{2}}{\mathrm{l}_{1 \_ \text {tune }}^{2}}+\frac{2}{3} \frac{\left(1-\frac{\mathrm{l}_{0}^{1} \mathrm{l}_{0} \text { tune }}{\mathrm{l}_{1 \_ \text {tune }}^{3}}\right) \mathrm{l}_{1_{1} \text { tune }} \theta}{\mathrm{g}_{\text {tune }}}\right. \\
& \left.+\frac{3}{4} \frac{\left(1-\frac{l_{0}^{4} \text { tune }}{1_{1_{-} \text {tune }}^{4}}\right) 1_{1_{-} \text {tune }}^{2} \theta^{2}}{\mathrm{~g}_{\text {tune }}^{2}}\right) \\
& =\mathrm{f}_{\text {II }}\left(\theta, \mathrm{g}_{\text {tune }}, \mathrm{V}_{\text {tune }}\right)
\end{aligned}
$$

By relating (7) to the rotational restoring force generated from the levering beam, the model for the actuation section is described as follows:

$$
\mathrm{f}_{\mathrm{II}}\left(\theta, \mathrm{g}_{\text {tune }}, \mathrm{V}_{\text {tune }}\right)=\mathrm{K}_{\mathrm{m}} \theta
$$

\section{Table 1 Dimensional parameters}

\begin{tabular}{ll}
\hline Parameters & Values \\
\hline g $_{\text {cap }}$ & $1 \mu \mathrm{m}$ \\
$g_{\text {tune }}$ & $1.4 \mu \mathrm{m}$ \\
$I_{3}$ & $560 \mu \mathrm{m}$ \\
$I_{2}$ & $360 \mu \mathrm{m}$ \\
$I_{\text {O_tune }}$ & $10 \mu \mathrm{m}$ \\
I__tune $_{1}$ & $80 \mu \mathrm{m}$ \\
I_control $_{\text {I_control }}$ & $50 \mu \mathrm{m}$ \\
$b$ & $100 \mu \mathrm{m}$ \\
$W$ & $500 \mu \mathrm{m}$ \\
$t$ & $10 \mu \mathrm{m}$ \\
I & $11 \mu \mathrm{m}$ \\
$G$ & $100 \mu \mathrm{m}$ \\
\hline
\end{tabular}
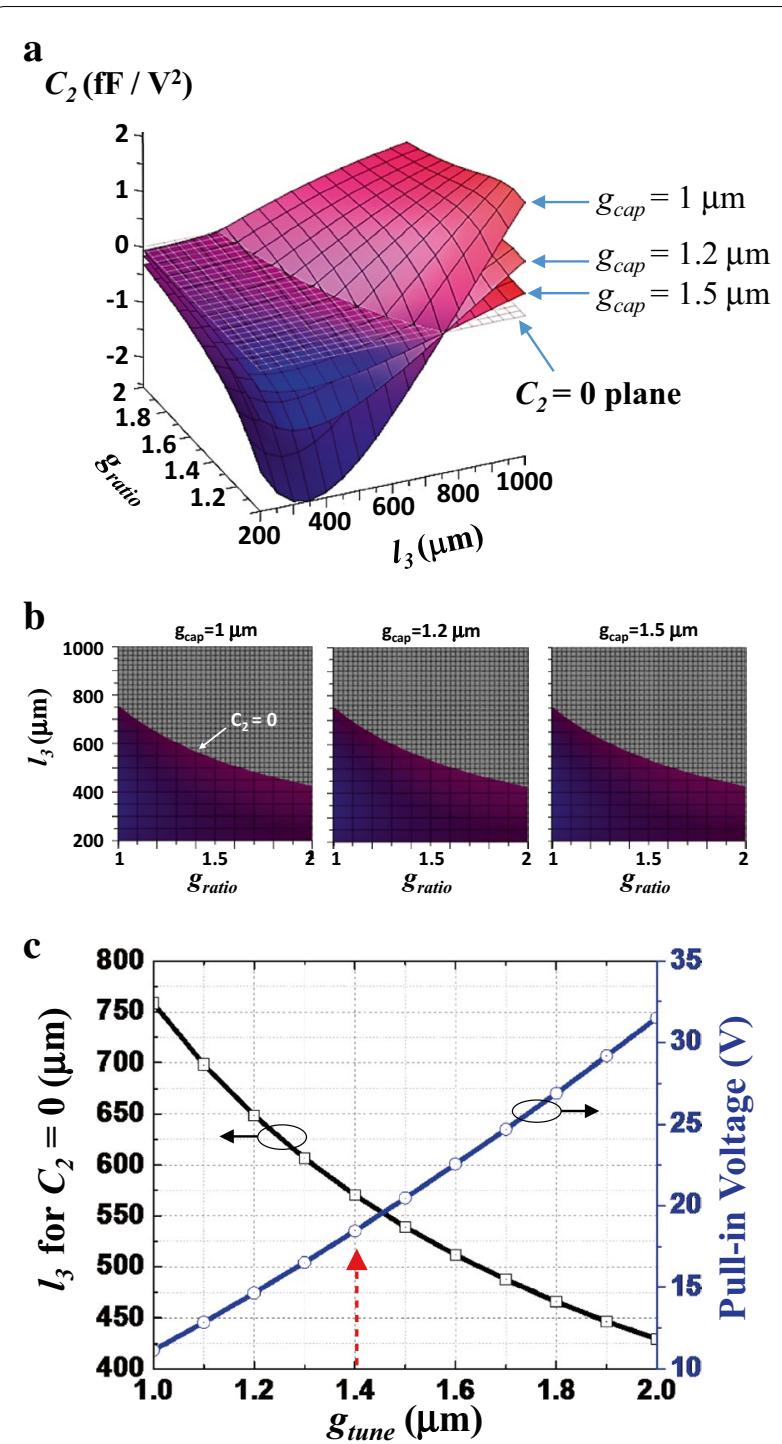

Fig. 3 Analysis of parameters that determine the linearity of $C-V$ response. a $3 \mathrm{D}$ plot for the coefficient of second order term in Taylor series. b Top view of (a) showing the cross points with $C_{2}=0$ plane are the same in every case. $\mathbf{c} l_{3}$ and pull-in voltage in the case of $g_{\text {cap }}=1 \mu \mathrm{m}$

where, $K_{m}$ is a rotational mechanical spring constant determined by the geometry of the levering beam [15].

As the final step, the $C-V$ response can be expressed by plugging (5) into (8). Logically, it can be expressed as follows:

$$
\begin{aligned}
& \mathrm{f}_{\mathrm{II}}\left(\mathrm{f}_{\mathrm{I}}\left(\mathrm{C}_{\text {cap }}, \mathrm{g}_{\text {cap }}, \mathrm{l}_{2}, \mathrm{l}_{3}\right), \mathrm{g}_{\text {tune }}, \mathrm{V}_{\text {tune }}\right) \\
& \quad=\mathrm{K}_{\mathrm{m}} \mathrm{f}_{\mathrm{I}}\left(\mathrm{C}_{\text {cap }}, \mathrm{g}_{\text {cap }}, \mathrm{l}_{2}, \mathrm{l}_{3}\right)
\end{aligned}
$$




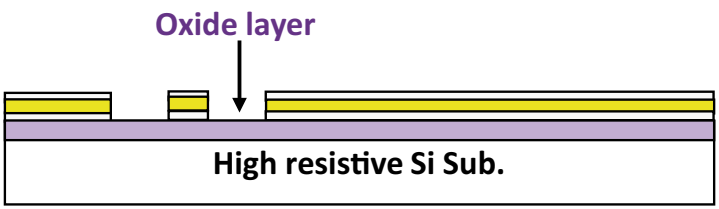

(1) $\mathrm{Ti}(500 \AA ̊) / \mathrm{Au}(2000 \AA ̊) / \mathrm{Ti}(50 \AA)$ evaporator, Bottom patterning

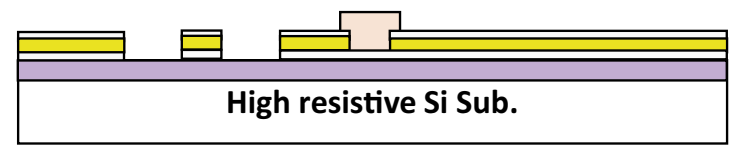

(3) Bottom bonding area patterning $(2 \mu \mathrm{m})$ covering H.R.C (BCB)

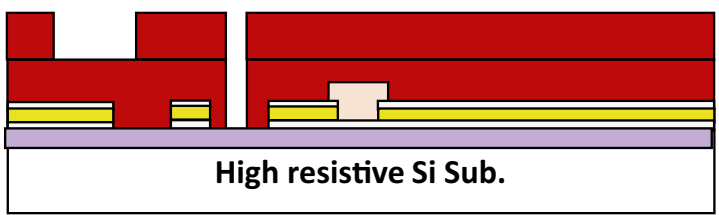

(5) AZ4330 : AZ1500 = $1: 1(0.5 \mu \mathrm{m})$ pattering, $150^{\circ} \mathrm{C}$ hard bake ( $3 \mathrm{~min}$ )

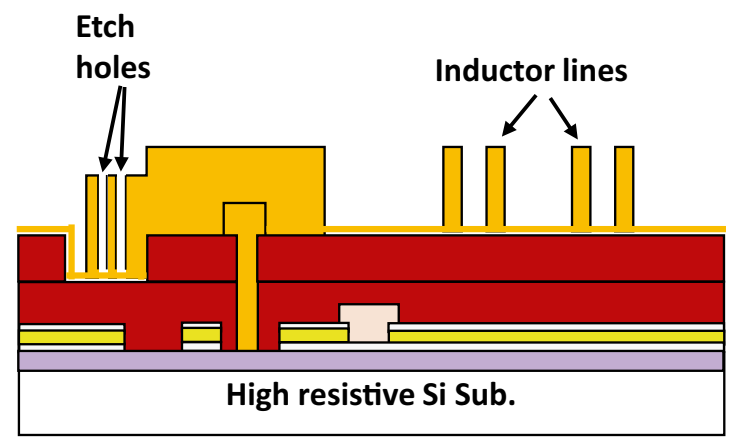

(7) Cu electroplating (actuator body \& inductor, $20 \mu \mathrm{m}$ )

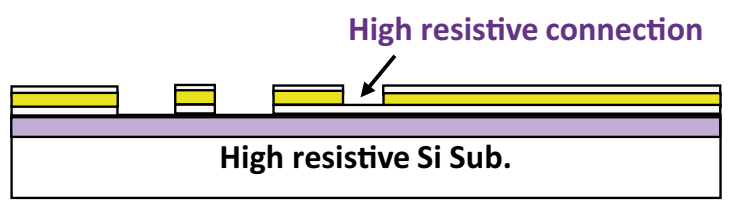

(2) Ti / Au patterning for high resistive connection (H.R.C)

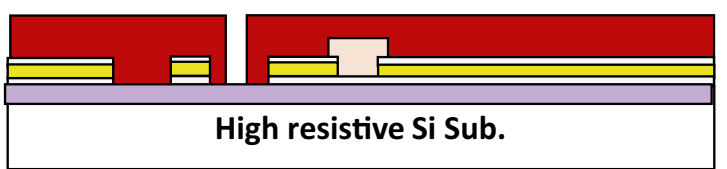

(4) AZ4330 : AZ1500 = $2: 1(1 \mu \mathrm{m})$ pattering, $150^{\circ} \mathrm{C}$ hard bake (5 min)

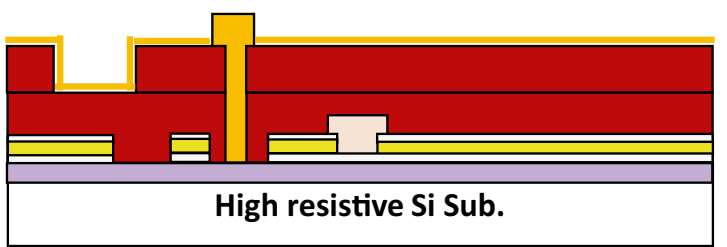

(6) Seed $\mathrm{Cu}$ deposition \& electroplating (levering beam, $10 \mu \mathrm{m}$ )

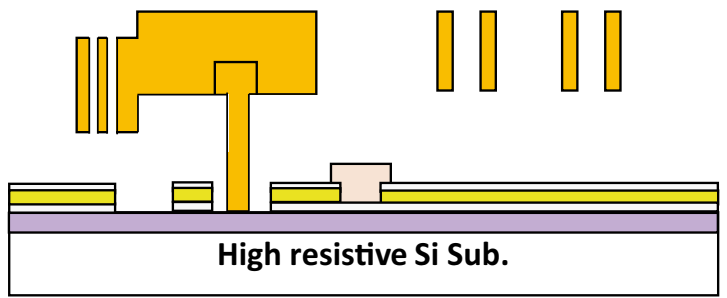

(8) Cu seed removal, Release (EKC 800) followed by CPD

Fig. 4 Fabrication process of the proposed linear frequency-tuned $L C$ resonator

The structural parameters which do not affect the linearity of $C-V$ response are pre-determined, as shown in Table 1 (parameters that are out of the solid-lined box). Regarding fabrication burden and measurable capacitance range, $l_{3}-l_{2}$ is fixed as $200 \mu \mathrm{m}$. Therefore (9) can be arranged as follows (the detailed equation is written in the appendix section at the end of this paper):

$$
\mathrm{C}_{\text {cap }}=\mathrm{f}_{\text {III }}\left(\mathrm{V}_{\text {tune }}, \mathrm{g}_{\text {tune }}, \mathrm{g}_{\text {cap }}, \mathrm{l}_{3}\right) .
$$

Now that the $C-V$ response equation is developed, the relationship among the variables can be analyzed by plotting the coefficient of the second order term in $C_{c a p}$ after expanding (10) in the Taylor series.

$$
\mathrm{C}_{2}=\frac{1}{2}\left(\frac{\mathrm{d}^{2} \mathrm{C}_{\text {cap }}}{\mathrm{dV}_{\text {tune }}^{2}}\right) \mid \mathrm{V}_{\text {tune }}=\mathrm{V}_{\mathrm{t}}, \quad \mathrm{V}_{\mathrm{t}}=\frac{\mathrm{V}_{\text {pull-in }}}{2}
$$

where, $C_{2}$ means the coefficient of the second order term of the Taylor series expansion. The linear shaped $C-V$ response is realized when $C_{2}$ is zero, otherwise, a concave or convex shape is achieved when $C_{2}$ has positive or negative values, respectively [13]. 

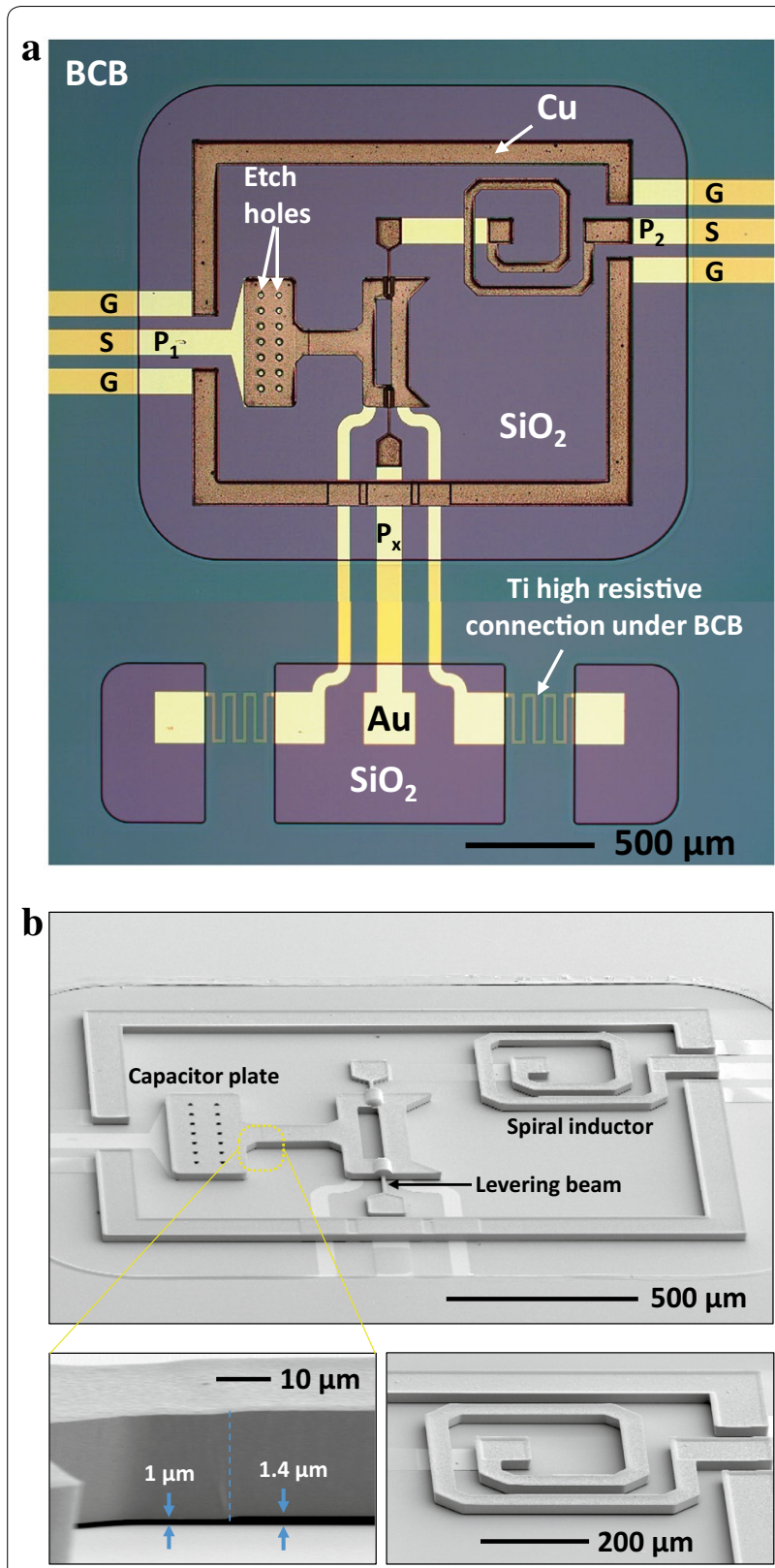

Fig. 5 Fabricated results. a Optical top view including electrical tipping pad below the $L C$ device. $\mathbf{b}$ SEM images of the proposed device (upper), magnified view of the actuator beam showing the height of $g_{\text {cap }}$ and $g_{\text {tune }}$ (lower left), and serially connected suspended spiral inductor (lower right)

Figure 3a represents the three dimensional plot of $C_{2}$ obtained by calculating (10) using (11) with several $g_{\text {cap }}$ cases. Since the length of $l_{2}$ is determined once $l_{3}$ is selected, we focused on the gap difference between the capacitor $\left(g_{\text {cap }}\right)$ and actuator section $\left(g_{\text {tune }}\right)$. Therefore, $C_{2}$ is depicted with respect to $l_{3}$ and $g_{\text {ratio }}\left(g_{\text {tune }} / g_{\text {cap }}\right)$. In the case of $g_{\text {cap }}=1 \mu \mathrm{m}$, it can be seen that the slope is higher than in the case of $g_{\text {cap }}=1.2$ and $1.5 \mu \mathrm{m}$ as $l_{3}$ changes. This means that the linearity of the $C-V$ response becomes more sensitive as the actuator length changes when the capacitor plate is closer to the bottom electrode. Another noticeable point is that all three $g_{\text {cap }}$ cases show the same values of $g_{\text {ratio }}$ and $l_{3}$, which make $C_{2}$ zero, as shown in Fig. 3b. This tells us that the absolute value of $g_{\text {cap }}$ and $g_{\text {tune }}$ is not important, however, the ratio of the two is the determining factor for making the initial $C-V$ response $\left(V_{\text {curve-control }}=0\right)$ linear. Figure $3 \mathrm{c}$ shows $l_{3}$ making $C_{2}$ zero and the corresponding pull-in voltages when $g_{\text {cap }}$ is $1 \mu \mathrm{m}$. The pull-in voltage is derived from (8), and it is determined only by $g_{\text {tune }}$ (the other geometrical dimension is already fixed in this work, and $\theta$ or $V_{\text {tune }}$ are not determinant factors for the pull-in voltage). As depicted in Fig. $3 \mathrm{c}, l_{3}$ can be shortened as $g_{\text {tune }}$ gets larger for the same result, which reduces the burden of fabricating a long suspended actuator beam. However, the increment of $g_{\text {tune }}$ results in an increase of the pull-in voltage. Therefore, a compromise point should be chosen considering the fabrication burden and available voltage level in the desired system. In this work, we chose $g_{\text {cap }}$ to be $1 \mu \mathrm{m}$ and $l_{3}$ to be $560 \mu \mathrm{m}$, and therefore, $g_{\text {tune }}$ is determined to be $1.4 \mu \mathrm{m}$. The calculated $C-V$ response is compared with the measured result in appendix section of this paper.

\section{Results and analysis}

\section{Fabrication}

The fabrication process for the proposed $L C$ resonator starts with a bottom metal patterning as shown in Fig. 4, step (1). The upper Ti layer (50 ̊) acts as an adhesion layer for the BCB. Since the device is supposed to handle an RF signal, the electrical pad for the $D C$ voltage application must be isolated using a highly electrically resistive material, which is formed by leaving the bottom thin Ti film (500 ̊) in this work (step 2). Then, BCB (Benzocyclobutene) is spin-coated, cured, and patterned using a polymer etcher to keep the high resistive connection from oxidizing, which would excessively increase the electrical resistance.

A photoresist (PR) is patterned two times as a sacrificial layer. The first $\mathrm{PR}$ is patterned and additionally cured at high temperature for hardening $\left(150{ }^{\circ} \mathrm{C}\right.$, step (4)) because the second PR is patterned on top of the first PR to form the capacitor section. The high temperature treatment changes the molecular structure of PR so that it is insensitive to UV light. In this way, a different thickness of PR sacrificial layer can be achieved, as shown in step (5). This difference realizes the desired gap ratio $\left(g_{\text {ratio }}\right)$ between the capacitor section and actuator section discussed in Fig. 3. After thermally evaporated $\mathrm{Cu}$ is deposited as a seed layer, the levering beam is formed by electroplating in step (6). In step (7), the capacitor and 


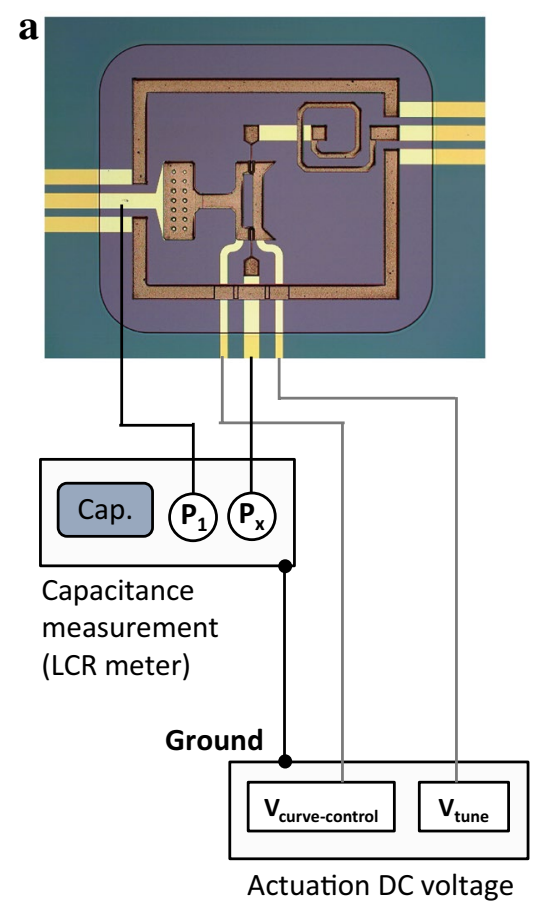

b LCR meter $(10 \mathrm{kHz}, 100 \mathrm{mV}$ amplitude)

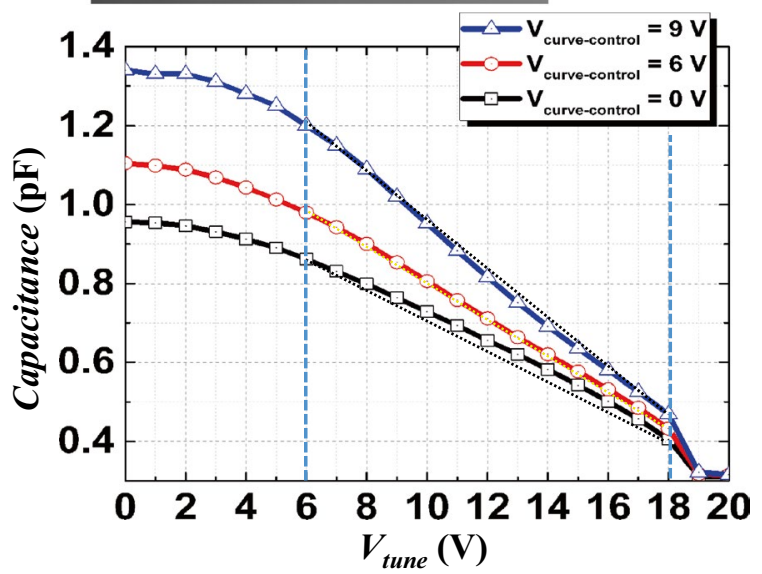

Fig. 6 Capacitance measured results. a Measurement setup. $\mathbf{b} C-V$ response of the capacitor device with respect to tuning voltage in several control voltage cases

inductor are formed, simultaneously. As the last step, the seed $\mathrm{Cu}$ layer and PR sacrificial layer are removed by respective wet etchants, followed by a critical point dryer $(\mathrm{CPD})$ release process.

Figure 5 shows the final $L C$ resonator device. From the top view, it can be seen that the capacitor and spiral inductor are serially connected through one end of the levering beam (upper image in Fig. 5a). The lower levering beam is connected to the electrode, $\mathrm{P}_{\mathrm{x}}$ that is used to measure only the $C-V$ response of the capacitor.

The difference in gap heights between the capacitor section and the actuator section was verified by scanning electron microscope (SEM) images, as shown in Fig. 5b. In the middle of the actuator beam, there is a specific point where the gap height is differently formed, so that it is $1 \mu \mathrm{m}$ in the capacitor section (left direction) and $1.4 \mu \mathrm{m}$ in the actuator section (right direction). The serially connected spiral inductor is suspended from the bottom with the same height as that of the actuator section $(1.4 \mu \mathrm{m})$.

\section{Measurements and analysis}

First, the $C-V$ response was measured to verify that the capacitor device had the desired tuning performance. Following the measurement setup shown in Fig. 6a, the $C-V$ response could be measured solely by tipping the points, $P_{1}$ and $P_{x}$. Figure $6 b$ represents the measured result. When we consider the $V_{\text {tune }}$ range from 6 to $18 \mathrm{~V}$, which is designated the actual usage region (depicted with sky blue colored dotted vertical lines), the $C-V$ response changes from convex to concave form as the curve control voltage $\left(V_{\text {curve-control }}\right)$ increases from 0 to $9 \mathrm{~V}$. When $V_{\text {tune }}$ is applied over $18 \mathrm{~V}$, the capacitance decreases abruptly due to the pull-in phenomenon in the actuator section.

Having the result of the $C-V$ response tuning performance, RF measurement was conducted using a vector network analyzer, as shown in Fig. 7a. Figure 7b represents the measured result of return and insertion loss when $V_{\text {curve-control }}$ is $9 \mathrm{~V}$. The case of $V_{\text {tune }}=20 \mathrm{~V}$ is overlapped with the case of $V_{\text {tune }}=22 \mathrm{~V}$ due to the pull-in phenomenon, which happened at $V_{\text {tune }}=19 \mathrm{~V}$, as shown in Fig. 6b. It can be seen that the return loss of the $L C$ resonator changes its resonant points (the lowest value of return loss) as $V_{\text {tune }}$ changes. By extracting the frequency that makes the return loss lowest, the $f-V$ response is finally acquired, as shown in Fig. 7c. The resonant frequency is tuned more and more linearly as $V_{\text {curve-control }}$ increases to $9 \mathrm{~V}$ in the actual usage region $\left(V_{\text {tune }}=6-18 \mathrm{~V}\right)$.

These results are well matched to the relationship between the $C-V$ response and $f-V$ response that we discussed previously. As expected from Fig. 1c, the linear $f-V$ response is achieved when the capacitor shows 

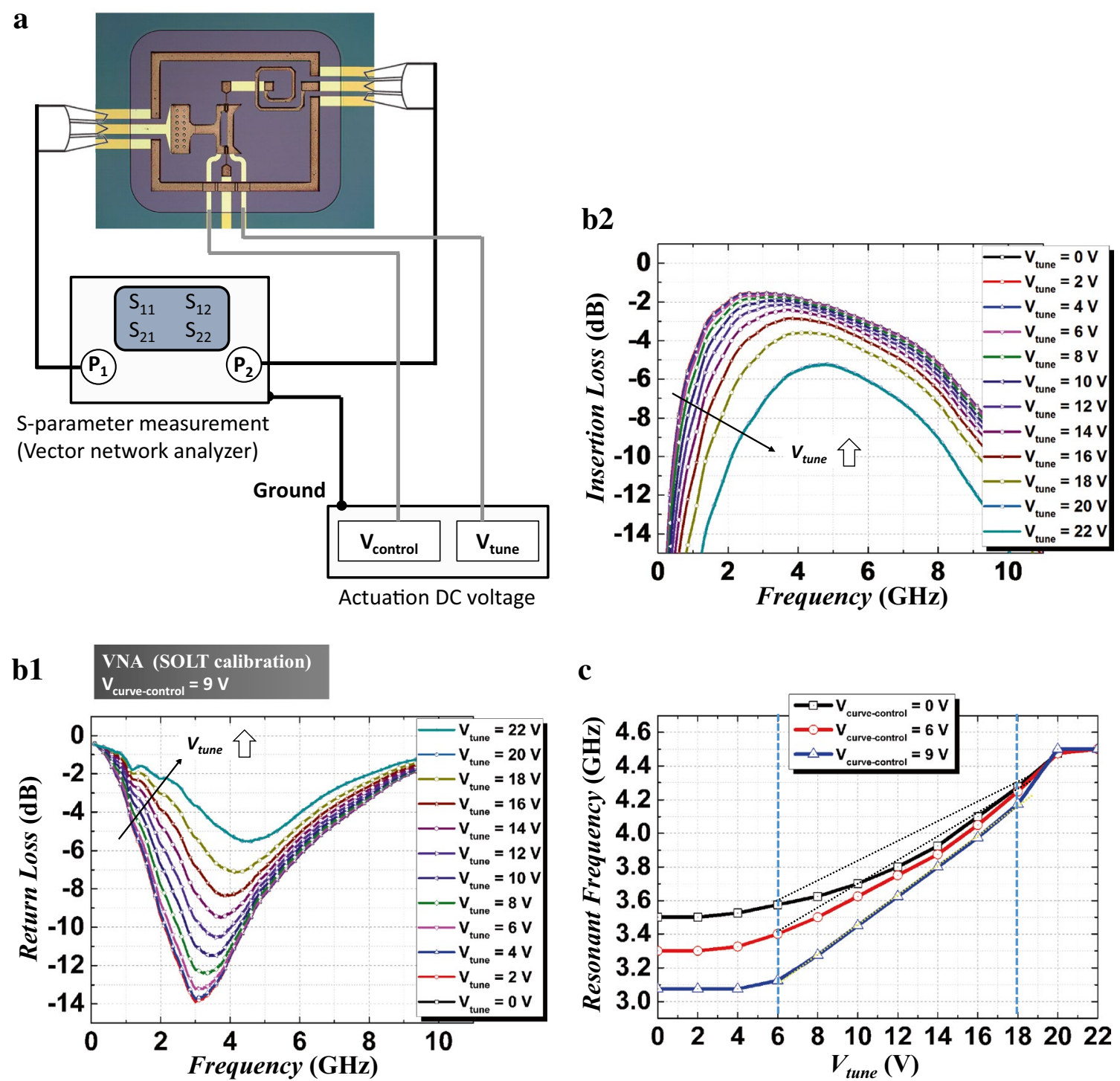

c

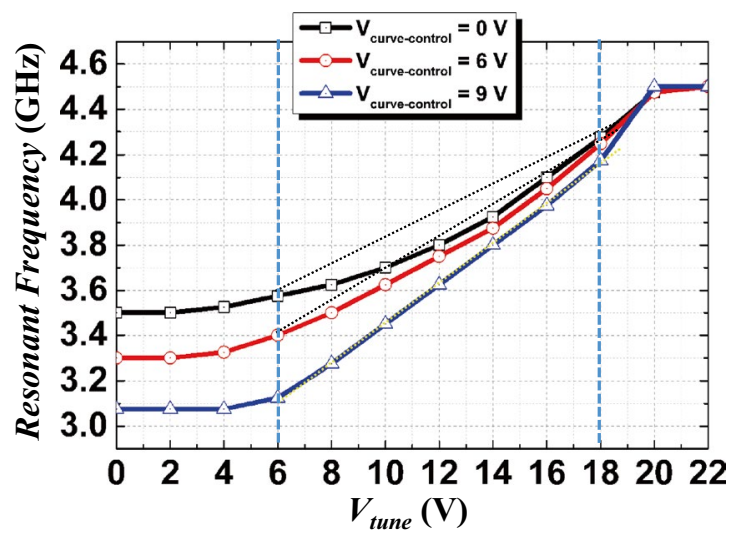

Fig. 7 Measured results. a Measurement setup. b Return loss and insertion loss with respect to frequency sweep. c Resonant frequency of the fabricated series $L C$ resonator according to $V_{\text {tune }}$

a concave $C-V$ response. This is the first experimental demonstration that the concave $C-V$ response results in a linear $f-V$ response in an $L C$ resonator module. In view of Q-factor, the proposed device did not show a high $\mathrm{Q}$ due to the fact that the RF signal should pass though the relatively narrow levering beam. This can be solved by changing the signal path by splitting the bottom electrode [16]. Additionally, increasing the thickness of the bottom plate would be an effective solution for the high Q-factor [17].

Two commercial products were compared in terms of the linearity of the $f-V$ response and their tuning range. Figure 8 shows the plots of the frequency tuning with respect to tuning voltage (Fig. 8a) and a summary table of their performance (Fig. 8b) [18]. As shown in Fig. 8a, the two commercial semiconductor based VCO have convex $f-V$ responses. It is assumed that the MOS varactors used in those products have severely concave $C-V$ responses $[19,20]$. Consequently, to achieve linear frequency tuning, those two VCOs must inevitably be connected to other extra circuits referred in the introduction section [4-6].

In contrast, the proposed $L C$ resonator has the capacity to control the shape of the $C-V$ response within the module, so that the resonant frequency can be linearly tuned without any external circuital supports. Since the 


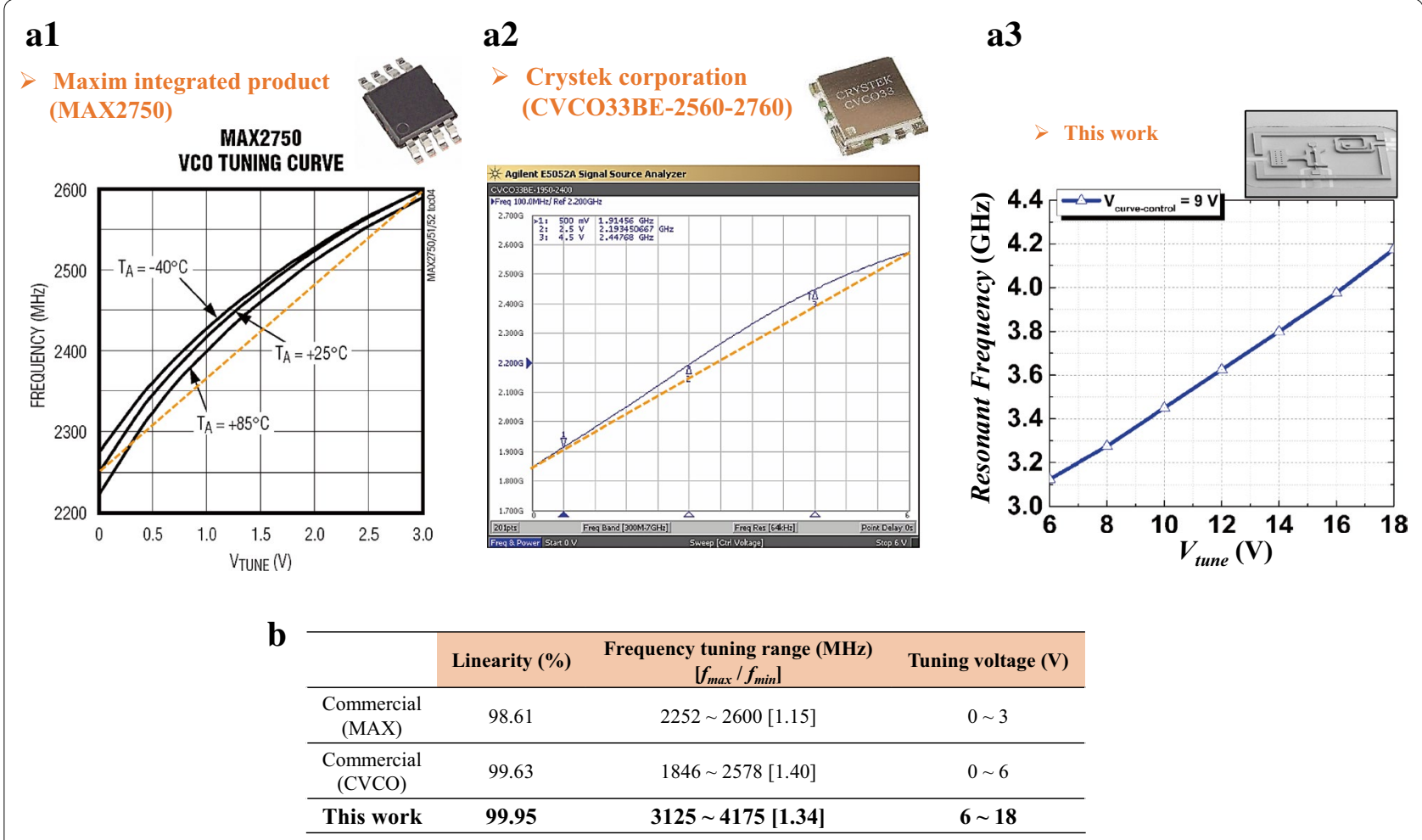

Fig. 8 Performance comparison. a $f-V$ response of commercial $V C O s$ and proposed $L C$ module. b Data for linearity, frequency tuning range, and tuning voltage

oscillation frequency of the VCOs is the resonant frequency of the inductor and varactor connected in parallel as discussed in the 'proposed concept and design' section, this high $f-V$ linearity is obviously expected to be shown even in the form of VCOs.

In addition to managing the frequency linearity, the proposed device is able to cover much wider range of resonant frequencies. This results in a much higher figure of merit, as shown in Fig. 8b.

\section{Conclusion}

In this paper, a device level approach was conducted to achieve linear output frequency tuning in an $L C$ resonant system. The proposed concept was successfully demonstrated using a developed $C-V$ response tunable MEMS varactor and a monolithically-integrated spiral inductor. The fabricated $L C$ module exhibited almost perfect linear frequency tuning characteristics, from 3.125 to $4.175 \mathrm{GHz}$ with a linearity factor of $99.95 \%$. Integration of the proposed MEMS capacitor with the VCO circuits could require an extra fabrication cost. However, since this device-level solution can reduce the complexity of RF circuits as well as relative power consumption, this development can be favorably considerable in multi-band RF system design.

\section{Authors' contributions}

$\mathrm{CHH}$ carried out overall design, fabrication, measurement and analysis of the results, and drafted the manuscript. YHY supported fabrication process and measurement. SDK analyzed failure issue of fabrication and made solutions especially sacrificial layer process. MHS suggested fabrication plan, method, and material selection. All authors participated in editing process of the final manuscript. All authors read and approved the final manuscript.

\section{Author details}

${ }^{1}$ School of Electrical Engineering, Korea Advanced Institute of Science and Technology (KAIST), 291 Daehak-ro, Yuseong-gu, Daejeon 34141, Republic of Korea. ${ }^{2}$ Present Address: Wireless Semiconductor Division of Broadcom, $8 \mathrm{~F}$ HiBrand, 16, Maeheon-ro, Seocho-gu, Seoul 06771, Republic of Korea.

\section{Acknowledgements}

We also thanks to members of our laboratory (3D micro-nano structures lab.) for sincere comments on this research.

\section{Competing interests}

The authors declare that they have no competing interests. 
Availability of data and materials

The datasets supporting the conclusions of this article are included within the article and its additional files.

\section{Funding}

This research was supported by the Center for Integrated Smart Sensors funded by the Ministry of Science, ICT \& Future Planning as "Global Frontier Project" (No. CISS-2012054187), and by Samsung Research Funding Center of Samsung Electronics under Project Number SRFC-IT1402-06.

\section{Appendix}

Equation (9) is expressed as (12). After applying the structural parameter values shown in table I, except the parameters surrounded by the solid line $\left(l_{2}\right.$ is expressed with $l_{3}$ according to the pre-determined relationship that $\left.l_{3}-l_{2}=200 \mu \mathrm{m}\right)(12)$ is simply re-written with only four variables as (13). decreases radically according to the increase in $V_{\text {tune }}$ when beam length $\left(l_{3}\right)$ is longer. Otherwise, $g_{\text {cap }}$ controls the effect of $B H$ to $C_{c a p}$, which means that when $g_{\text {cap }}$ is high, the rate of capacitance change $\left(C_{\text {cap }}\right)$ to $V_{\text {tune }}$ is low. This analytical model properly describes our structural intuition.

The proposed device is expected to have the mechanical resonance at several $\mathrm{kHz}$. Figure 10 shows the simulated result of the proposed device, which represent the mechanical resonant frequency is $2.545 \mathrm{kHz}$. This result roughly means that it takes about $0.4 \mathrm{~ms}$ to move the capacitance back and forth between two values.

$$
\begin{aligned}
& \frac{\varepsilon \mathrm{bV}_{\text {tune }}^{2} \mathrm{l}_{1 \_ \text {tune }}^{2}}{2 \mathrm{~g}_{\text {tune }}^{2}}\left(\frac{1}{2}-\frac{1}{2} \frac{\mathrm{l}_{0 \_ \text {tune }}^{2}}{\mathrm{l}_{1 \_ \text {tune }}^{2}}+\frac{4}{3} \frac{\left(1-\frac{\mathrm{l}_{0 \_ \text {tune }}^{3}}{\mathrm{l}_{1 \_ \text {tune }}^{3}}\right)\left(\frac{\varepsilon \mathrm{b}\left(\mathrm{l}_{3}-\mathrm{l}_{2}\right)}{\mathrm{C}_{\text {cap }}}-\mathrm{g}_{\text {cap }}\right) \mathrm{l}_{1 \_ \text {tune }}}{\left(\mathrm{l}_{3}+\mathrm{l}_{2}\right) \mathrm{g}_{\text {tune }}}+\frac{3\left(1-\frac{\mathrm{l}_{0 \_ \text {tune }}^{4}}{\mathrm{l}_{1 \_ \text {tune }}^{4}}\right)\left(\frac{\varepsilon \mathrm{b}\left(\mathrm{l}_{3}-\mathrm{l}_{2}\right)}{\mathrm{C}_{\text {cap }}}-\mathrm{g}_{\text {cap }}\right)^{2} \mathrm{l}_{1 \_ \text {tune }}^{2}}{\left(\mathrm{l}_{3}+\mathrm{l}_{2}\right)^{2} \mathrm{~g}_{\text {tune }}^{2}}\right) \\
& =\frac{2 \mathrm{~K}_{\mathrm{m}}\left(\frac{\varepsilon \mathrm{b}\left(\mathrm{l}_{3}-\mathrm{l}_{2}\right)}{\mathrm{C}_{c a p}}-\mathrm{g}_{c a p}\right)}{\mathrm{l}_{3}+\mathrm{l}_{2}} \\
& \frac{1.42 \times 10^{-23} \mathrm{~V}_{\text {tune }}^{2}}{\mathrm{~g}_{\text {tune }}^{2}}\left(0.49+\frac{1.06 \times 10^{-4}\left(\frac{8.85 \times 10^{-19}}{\mathrm{C}_{\text {cap }}}-\mathrm{g}_{\text {cap }}\right)}{\left(2 \mathrm{l}_{3}-2 \times 10^{-4}\right) \mathrm{g}_{\text {tune }}}+\frac{1.92 \times 10^{-8}\left(\frac{8.85 \times 10^{-19}}{\mathrm{C}_{\text {cap }}}-\mathrm{g}_{\text {cap }}\right)^{2}}{\left(2 \mathrm{l}_{3}-2 \times 10^{-4}\right)^{2} \mathrm{~g}_{\text {tune }}^{2}}\right) \\
& =\frac{6.74 \times 10^{-7}\left(\frac{8.85 \times 10^{-19}}{\mathrm{C}_{c a p}}-\mathrm{g}_{\text {cap }}\right)}{2 \mathrm{l}_{3}-2 \times 10^{-4}}
\end{aligned}
$$

For the Taylor expansion, (13) should be arranged by $C_{\text {cap }}$ as shown in (14). According to (14), $C_{\text {cap }}$ is categorized in the capacitor section $\left(g_{\text {cap }}\right)$, actuator section $(H$ : $g_{\text {tune }}$ and $\left.V_{\text {tune }}\right)$, and actuator beam length related parameter $\left(B: l_{3}\right)$.

$$
\begin{aligned}
& \mathrm{C}_{\text {cap }}=\mathrm{f}_{\mathrm{III}}\left(\mathrm{V}_{\text {tune }}, \mathrm{g}_{\text {tune }}, \mathrm{g}_{\text {cap }}, \mathrm{l}_{3}\right)=\frac{8.85 \times 10^{-19}}{\mathrm{BH}+\mathrm{g}_{\text {cap }}} \\
& \mathrm{H}=\mathrm{g}_{\text {tune }}\left\{\left(\frac{1.26 \times 10^{24} \mathrm{~g}_{\text {tune }}^{3}}{\mathrm{~V}_{\text {tune }}^{2}}-2.79 \times 10^{3}\right)\right. \\
& \left.-\sqrt{\left(\frac{1.26 \times 10^{24} \mathrm{~g}_{\text {tune }}^{3}}{\mathrm{~V}_{\text {tune }}^{2}}-2.79 \times 10^{3}\right)^{2}-2.58 \times 10^{7}}\right\} \\
& \mathrm{B}=\mathrm{l}_{3}+\mathrm{l}_{2}=2 \mathrm{l}_{3}-200 \times 10^{-6}
\end{aligned}
$$

According to Fig. 9, $g_{\text {tune }}$ determines the sensitivity of $H$ to $V_{\text {tune }}$. As $g_{\text {tune }}$ becomes smaller, the rate of change of $H$ becomes greater with respect to the change of $V_{\text {tune }}$. It is also notable that $l_{3}$ affects the sensitivity of $H$; $C_{c a p}$
Figure 11a represents the calculated result of the proposed capacitor's $C-V$ response using the model in the 'design of the structural parameters' section and the measured result. By adding the parasitic capacitance component on the capacitor plate and the tuning electrode, those two values are well matched as shown in Fig. 11b. To compensate the initial capacitance (value at $V_{\text {tune }}=0 \mathrm{~V}$ ), the structural parameter, $b$ was increased by $45 \mu \mathrm{m}$ representing the parasitic capacitance. In terms of the tuning plate, since there exists two triangle shaped stopper at the end of the plate, the attractive force between the tuning plate and the tuning electrode is increased due to the increased parasitic capacitance. Therefore, we increased $l_{1 \text { tune }}$ by $6.5 \mu \mathrm{m}$. Although this modification is well matched in the initial and the end of the tuning region, there is still a mismatched region in the middle. We consider this is because the levering beam sinks down a little when the control and the tuning voltages are applied simultaneously, which is not included in the model.

See Figs. 9, 10 and 11. 


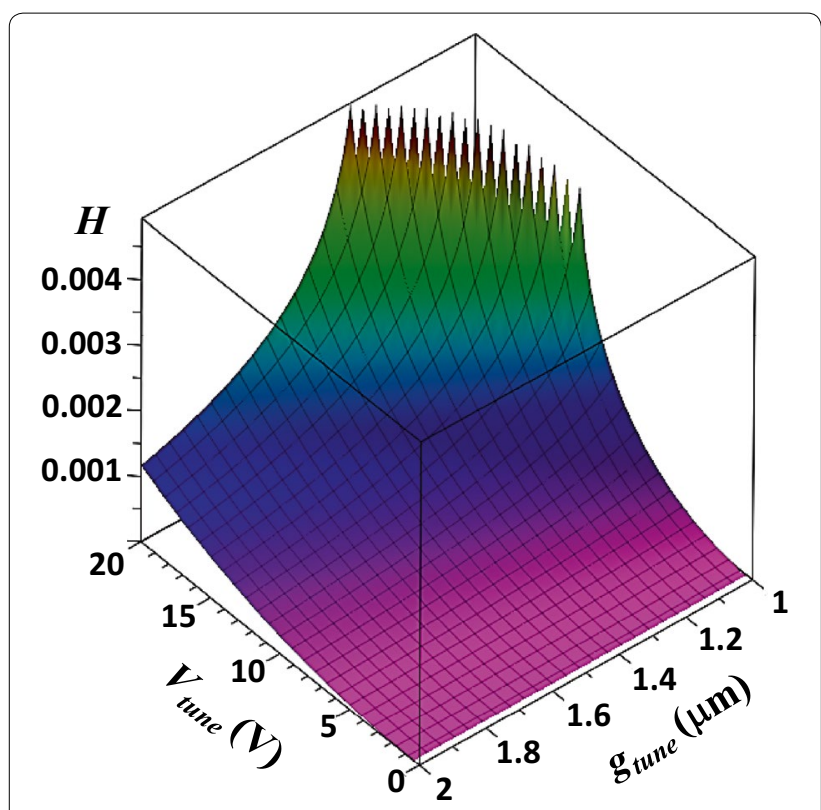

Fig. $93 \mathrm{D}$ plot of $H$ with respect to $V_{\text {tune }}$ and $g_{\text {tune }}$

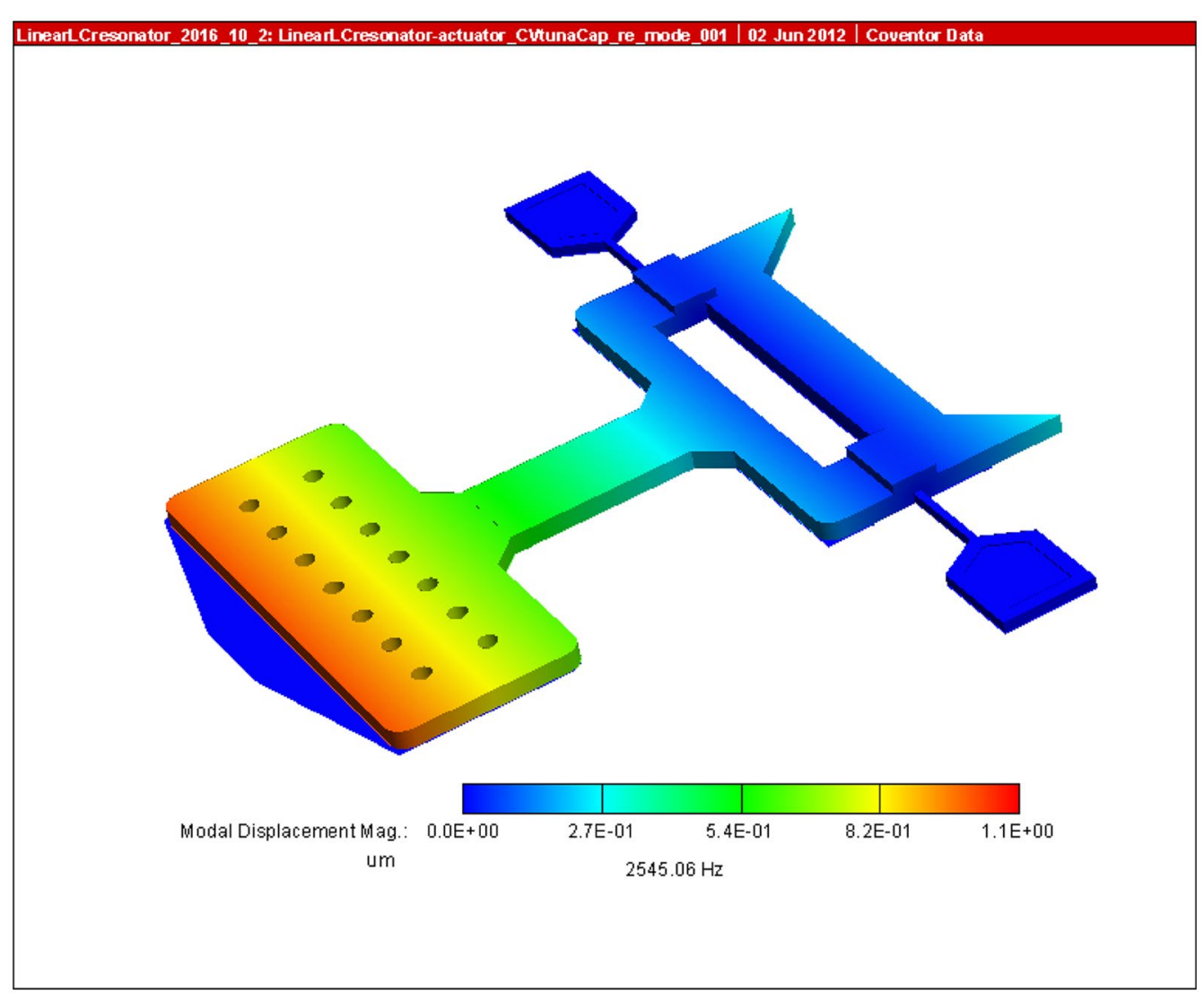

Fig. 10 CoventorWare ${ }^{\mathrm{TM}}$ simulation result of mechanical resonance. It occurs at $2.545 \mathrm{kHz}$ 

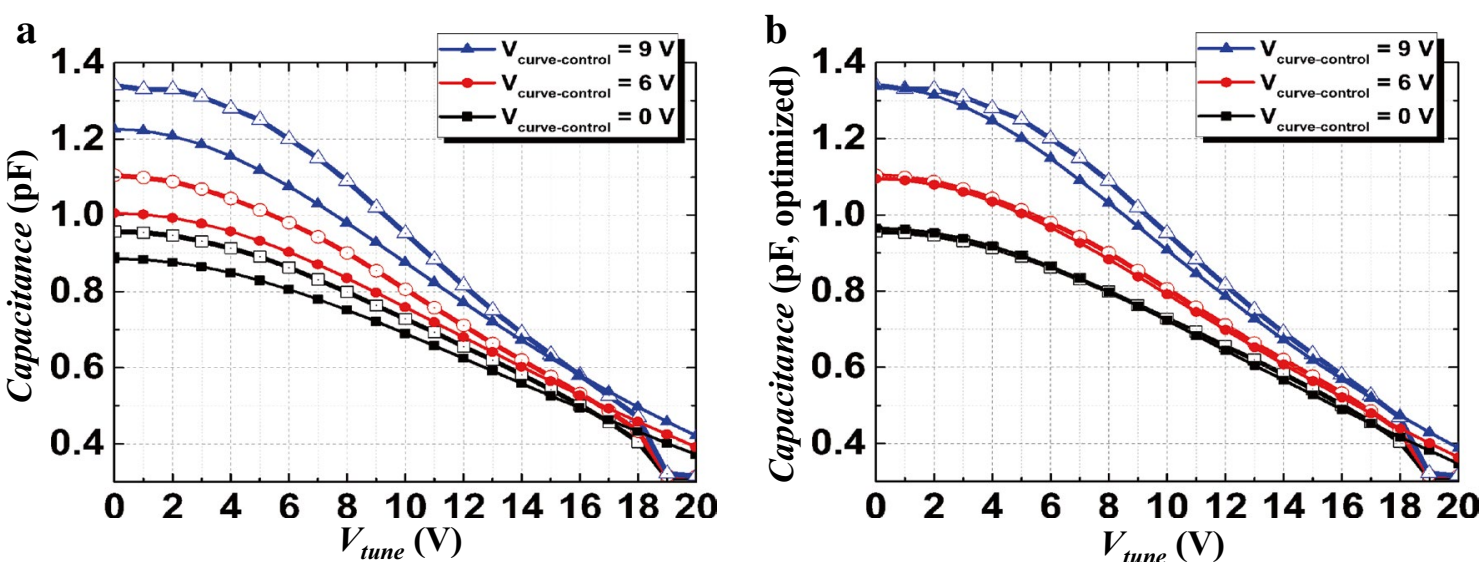

Fig. 11 Comparison of the calculated and measured $C-V$ response of the proposed capacitor. a Pure comparison. b Modified comparison result including optimization factor (parasitic capacitance)

\section{Publisher's Note}

Springer Nature remains neutral with regard to jurisdictional claims in published maps and institutional affiliations.

Received: 19 March 2017 Accepted: 30 August 2017 Published online: 04 September 2017

\section{References}

1. Brennan PV, Huang Y, Ash M, Chetty K (2011) Determination of sweep linearity requirements in FMCW radar systems based on simple voltage-controlled oscillator sources. IEEE Trans Aerosp Electron Syst 47:1594-1604

2. Wu T, Hanumolu PK, Mayaram K, Moon U-K (2009) Method for a constant loop bandwidth in LC-VCO PLL frequency synthesizers. IEEE I Solid State Circuits 44:427-435

3. Razavi B (2001) Design of analog CMOS integrated circuits. McGraw-Hill, New York

4. Kwon H, Kang B (2005) Linear frequency modulation of voltage-controlled oscillator using delay-line feedback. IEEE Microw Compon Lett 15:431-433

5. Koo K-H, Yoon S-W, Kim C-W (2009) A 34\% tuning range CMOS VCO with linear frequency tuning. In: Paper presented at IEEE radio wireless symposium, pp 288-291

6. Jianwei L, Xiaohui Q (2012) Study on linearity correction scheme for VCO tuning characteristics. Appl Mech Mater 130-134:4178-4184

7. Liu X, Katehi LPB, Chappell WJ, Peroulis D (2010) High-Q tunable microwave cavity resonators and filters using SOI-Based RF MEMS tuners. J Microelectromech Syst 19:774-784

8. Shim Y, Wu Z, Rais-Zadeh M (2012) A multimetal surface micromachining process for tunable RF MEMS passives. J Microelectromech Syst 21:867-874

9. Grichener A, Lakshminarayanan B, Rebeiz GM (2008) High-Q RF MEMS capacitor with digital/analog tuning capabilities. In: IEEE MTT-S international microwave symposium digest, Atlanta. pp 1283-1286

10. Mahameed R, Rebeiz GM (2010) Electrostatic RF MEMS tunable capacitors with analog tunability and low temperature sensitivity. In: IEEE MTT-S international microwave symposium digest, Anaheim. pp 1254-1257

11. Barrière $F$, Passerieux D, Mardivirin D, Pothier A, Blondy P (2012) An inverted-gap analog tuning RF-MEMS capacitor with 250 milliwatts power handling capability. In: Proceedings IEEE MEMS, Paris. pp 676-679
12. Han C-H, Choi D-H, Yang H-H, Yoon J-B (2011) Parallel plate MEMS variable capacitor with superior linearity and large tuning ratio using a levering structure. J Microelectromech Syst 20:1345-1354

13. Han C-H, Choi D-H, Yang H-H, Yoon Y-H, Yoon J-B (2013) Voltage-controlled $\mathrm{C}-\mathrm{V}$ response tuning in a parallel plate MEMS variable capacitor. J Microelectromech Syst 22:1403-1413

14. Degani O, Socher E, Lipson A, Leitner T, Setter DJ, Kaldor S, Nemirovsky Y (1998) Pull-in study of an electrostatic torsion microactuator. J Microelectromech Syst 7:373-379

15. Timoshenko SP, Goodier IN (1970) Theory of elasticity. McGraw-Hill, NewYork

16. Lee HS, Yoon YJ, Choi D-H, Yoon J-B (2008) High-Q, tunable-gap MEMS variable capacitor actuated with an electrically floating plate. In: Proceedings IEEE MEMS 2008, Tucson. pp 180-183

17. Lee HS (2010) MEMS-based high performance tunable passive components for RF applications. Doctoral Thesis, Department of Electrical Engineering, KAIST, Korea

18. Weisstein EW (2015) Math world, correlation coefficient. A Wolfram web resource. http://mathworld.wolfram.com/CorrelationCoefficient.html. Accessed 1 Dec 2015

19. Rogers JWM, Macedo JA, Plett C (2000) The effect of varactor nonlinearity on the phase noise of completely integrated VCOs. IEEE J Solid State Circuits 35:1360-1367

20. Kurachi S, Yoshimasu T, Itoh N, Yonemura K (2007) 5-GHz band highly linear VCO IC with a novel resonant circuit. In: Proceedings IEEE topical meeting silicon monolithic integrated circuits RF system, pp 285-288

\section{Submit your manuscript to a SpringerOpen ${ }^{\odot}$ journal and benefit from:}

- Convenient online submission

$\checkmark$ Rigorous peer review

- Open access: articles freely available online

- High visibility within the field

- Retaining the copyright to your article

Submit your next manuscript at $\boldsymbol{\nabla}$ springeropen.com 